\title{
Interpretación ontoepistemológica de Jaspers y Heidegger desde Holzapfel
}

\author{
Ontoepistemological interpretation of JASPers ANd Heidegger from Holzapfel
}

Hugo Campos-Winter (hugo.campos@uach.cl) Facultad de Filosofía y Humanidades, Universidad Austral de Chile (Valdivia, Chile) ORCID: 0000-0002-5039-9932

\begin{abstract}
This article intends to interpret the thoughts of Karl Jaspers and Martin Heidegger with the parameters amalgam and synergy of Cristóbal Holzapfel in order to propose an ontoepistemology of the social and human sciences. For this objective, a comparative analysis is carried out between the main existential structures of the existential enlightenment present in "Philosophy II" of Jaspers and the existential analytic present in "Being and time" of Heidegger. From the amalgams evidenced between the two analytics, certain existential are deduced that are analyzed in their epistemic synergy and projected towards the outline of a possible ontoepistemology based on the structures: concept of human being, subject-object relationship (conscience) and researcher-researched relationship (research ethics). It was obtained a situated and projective conception of the human being, a subject-object relationship as a complex cleavage and a researcher-researched relationship founded on an existential communication framed in the discursive tradition of their respective semiotic community.
\end{abstract}

Key words: Jaspers, Heidegger, human being, subject-object, researcher-researched.

\section{Resumen}

Este artículo tiene como propósito interpretar los pensamientos de Karl Jaspers y Martin Heidegger con los parámetros amalgama y sinergia de Cristóbal Holzapfel, y a partir de estos derivar proyecciones hacia la ontoepistemología de las ciencias sociales y humanas. Para esto se lleva a cabo un análisis comparativo entre las principales estructuras existenciales del esclarecimiento existencial presente en "Filosofía II" de Jaspers y la analítica existencial presente en "Ser y tiempo" de Heidegger. A partir de las amalgamas evidenciadas entre ambas analíticas se deducen determinados existenciales que son analizados en su sinergia epistémica y proyectados hacia el esbozo de una posible ontoepistemología con base en las estructuras: concepto de ser humano, relación sujeto-objeto (conciencia) y relación investigadorinvestigado (ética de investigación). Se obtuvo una concepción situada y proyectiva de ser humano, una relación sujeto-objeto como escisión compleja y una relación investigador-investigado fundada en una comunicación existencial enmarcada en la tradición discursiva de su respectiva comunidad semiótica.

Palabras clave: Jaspers, Heidegger, ser humano, sujeto-objeto, investigador-investigado. 


\section{Introducción}

El pensamiento de Karl Jaspers y Martin Heidegger marcó profundamente la filosofía y las ciencias humanas de occidente en el siglo XX, y continúa proyectando su influencia hacia el esclarecimiento del siglo XXI. Asociados al existencialismo, primero Jaspers y luego Heidegger, fundaron el giro en la filosofía desde las esencias universales y necesarias hacia la reflexión sobre la existencia, "la esencia del Dasein consiste en su existencia" (Heidegger 2015:69). Las reflexiones originales de ambos filósofos son fuentes inagotables de ideas y modelos del pensar filosófico. Asimismo, son torrentes de información que pueden permear y poner en movimiento la reflexión epistemológica al interior de la ciencia tradicional, la cual tiende a estancarse en categorías abstractas y descontextualizadas cuando un paradigma como el positivista se hace hegemónico. En cierta medida, esta investigación pretende continuar desde una perspectiva epistémica con el espíritu transgresor y de ilimitación de estos filósofos que en su momento conformaron una "comunidad de lucha" (Holzapfel 2007:141) de frente a la filosofía hegemónica de su tiempo.

Ambos pensadores inician y cultivan en la década de 1920 una fructífera amistad que se desarrolla hasta 1933, reflejada en largas estadías de Heidegger en casa de los Jaspers, en el momento en que aquél se iniciaba en el mundo académico como asistente de Husserl en la Universidad de Friburgo y Jaspers comenzaba su carrera como profesor de Filosofía en Heidelberg. Según el filósofo Cristóbal Holzapfel (2001:81), esta amistad se origina en el contexto de una relativa marginalidad con respecto a la filosofía oficial de esa época en Alemania, que a decir de Jaspers y Heidegger era una "filosofía escolar". La condición de profesor de filosofía llegado desde la psiquiatría por parte de Jaspers y de asistente por parte de Heidegger, contribuye a dicha marginalidad académica y a una relativa soledad que hace que ambos pensadores "puedan y tengan que concentrarse en el desarrollo de su pensamiento de largo alcance" (Holzapfel 2001:81) y en la conformación de la nombrada "comunidad de lucha", propuesta por Heidegger, que "encuentra inmediata acogida en Jaspers y que seguirá vigente a lo largo de gran parte de sus vidas" (Holzapfel 2001:81).

La relación de amistad, la relativa marginalidad y aislamiento con respecto a la filosofía oficial de Alemania, y la consecuente conformación de una "comunidad de lucha", habrían generado una influencia mutua y sobre todo un influjo del pensamiento de Jaspers en el pensamiento de Heidegger, a partir de las obras "Psicopatología General" de 1913 y "Psicología de las Concepciones de Mundo" de 1919, esta última reseñada por Heidegger. Asimismo, Heidegger tiene acceso ya en 1927 al manuscrito de "Filosofía", principal obra de Jaspers, fecha en que publica "Ser y Tiempo".

Holzapfel señala al respecto que en la obra "Filosofía II" de Jaspers, varios existenciales: "por ejemplo, desde luego existencia, pero también posibilidad, libertad, culpabilidad, resolución se encuentran desarrollados allí, y con alcances muy similares a los que éstos tendrían en el pensamiento heideggeriano, especialmente en lo que atañe a Ser y tiempo" (2001:80). Cabe señalar que, sin perjuicio de estas similitudes, ambos pensamientos brillan individualmente por la originalidad de cada escrito, por el énfasis y tratamiento que cada autor da a determinadas estructuras existenciales y por los aportes respectivos únicamente a cada autor, por ejemplo, el énfasis de Heidegger en la ontología y de Jaspers en la libertad existencial. No obstante la estrecha relación de amistad de la "comunidad de lucha" y la influencia teórica de Jaspers sobre Heidegger, Holzapfel señala que "hasta ahora la influencia que Jaspers ejerciera sobre Heidegger no ha sido debidamente analizada, si bien hay algunos escritos que tocan, pero tan solo parcialmente, el tema" (2001:81). 
La presente investigación se fundamenta en esta temática con el fin de analizar las sinergias epistémicas y proyectar consecuencias epistemológicas relativas a la concepción de ser humano, a la relación sujetoobjeto y a la relación investigador-investigado a partir de las amalgamas entre el esclarecimiento de la existencia de Jaspers y la analítica existencial de Heidegger. Respecto a los parámetros de amalgama y sinergia, Holzapfel plantea que "las concepciones antropológicas que tienen mayor afinidad entre sí se amalgaman y generan efectos sinergéticos" (2014:33), razonamiento que con base en lo planteado en este apartado sobre la "comunidad de lucha" entre Jaspers y Heidegger, es extrapolado a las afinidades en las estructuras existenciales que ambos autores comparten.

\section{Método}

Debido a la magnitud del pensamiento de cada autor, la presentación de la obra de ambos pensadores requiere una especificación del método de investigación. Por lo pronto, cabe afirmar junto con Jaspers la inevitabilidad de la reducción esquemática de toda investigación teórica, más aun considerando los límites estructurales de un artículo científico, contrapuestos a los pensamientos originales desde los que obtenemos el material para las presentes reflexiones, caracterizados por su amplitud y complejidad. En consecuencia, para llevar a cabo esta investigación se sigue el método de estudio de Kierkegaard que desarrolla Jaspers: "intentamos con ello reunir sus frases tomándolas de las diferentes obras, construir, completar y, sobre todo, dejar a un lado lo que nos pareció irrelevante para el fin presente (...) Quien quiera conocer a Kierkegaard, hará bien en leerlo a él mismo, pues aquí no está referido en razón de sí mismo, sino del problema, por lo que 'tal vez' le hayamos hecho alguna violencia" (Jaspers 1967:540).

El principio de rigor metodológico de esta investigación se hace eco de las palabras anteriores, conservando la especificidad de su método y objeto, a saber, el análisis comparativo en busca de amalgamas, sinergias y proyecciones epistémicas del pensamiento de Jaspers y Heidegger. De este modo, en primer lugar, se realizó una exégesis muy resumida, esquemática y a la vez comparativa de las principales confluencias en las estructuras existenciales del esclarecimiento de la existencia de Jaspers, presente en su obra "Filosofía II" y de la analítica existencial de Heidegger, presente en su obra "Ser y tiempo". Lo principal de este momento, fue el esfuerzo del entendimiento por poner "un poco de orden en todo aquello que en particular se ha percibido instintivamente como importante" (Jaspers 1967:37). En segundo lugar, y desde las confluencias entre los existenciales de ambos métodos, se dedujeron las estructuras ontoepistemológicas: concepto de ser humano, relación sujeto-objeto y relación investigadorinvestigado. Finalmente, se realizaron análisis de las sinergias y proyecciones epistémicas de las estructuras ontoepistemológicas obtenidas, mediante contraste con los significados que se les otorgan a dichas estructuras desde de la ciencia tradicional.

El constructo estructura ontoepistemológica refiere a la imposibilidad de representar con categorías descontextualizadas, como por ejemplo res cogitans y res extensa, la condición existencial del ser humano, de la relación sujeto-objeto y de la relación investigador-investigado. Con estructura queremos decir el complejo de disposiciones que constituyen el existir humano, como el hecho de proyectarse estando ya en el mundo entre los entes intramundanos. Con ontoepistemológica, se asume que ese conjunto de disposiciones emerge en las prácticas de conocimiento, de tal modo que todo acto de interpretación, ya sea lo a la mano instrumental o lo a la vista teórico, implica un acto comprensivo co-originario del objeto de conocimiento y del sujeto situado y proyectante, del mundo que co-emerge con el sujeto y el objeto, y del otro sujeto en comunicación existencial en el caso de la relación investigador-investigado. Siendo así la realidad un resultado de tales disposiciones, más que algo pre-dado por descubrir y conocer. 


\section{Amalgamas entre el esclarecimiento de la existencia en Jaspers y la analítica existencial en Heidegger}

La riqueza del pensamiento de ambos autores descansa principalmente en la reflexión acerca del salto desde la existencia empírica hacia la existencia propiamente tal. En el caso de Jaspers: "Todas las formas de este salto conducen (...) desde la existencia empírica a la existencia, a la que estaba encerrada germinalmente" (1958:76); o desde la facticidad de la caída del Dasein, en cuanto: "estar-en-el-mundo de un ente intramundano, en forma tal que este ente se pueda comprender como ligado en su destino al ser del ente que comparece para él dentro de su propio mundo" en el caso de Heidegger (2015:84). Este salto se da en Jaspers en las situaciones límites (muerte, sufrimiento, lucha, culpa) en las que el existente se encuentra inmerso o caído originariamente y a las cuales el posible existente responde despertando en su existencia con la posibilidad de ser-sí-mismo: "Ante las situaciones límites no reaccionamos, por tanto, inteligentemente, mediante planes y cálculos para superarlas, sino por una actividad completamente distinta, llegando a ser la posible existencia que hay en nosotros; llegamos a ser nosotros mismos entrando en situaciones límite con los ojos bien abiertos. Estas solo son cognoscibles externamente para el saber; como realidades sólo pueden ser sentidas por la existencia. Experimentar las situaciones límites y existir son una misma cosa" (Jaspers 1958:67).

Las acciones que nos permiten el salto desde la situación límite son las acciones indeterminadas en tanto producto de una voluntad de libertad que se quiere a sí misma. Las acciones incondicionadas son entonces el origen del existente cierto de sí mismo: "en el actuar del hombre puede estar presente algo distinto, por lo cual ese obrar se retrae de la sin finitud temporal, replegándose en un ser-sí-mismo que al actuar está cierto de sí (...) Lo llamamos acción incondicionada (...) La acción está vinculada a las situaciones en el mundo. Como acción incondicionada se realiza a la vez en la situación límite" (Jaspers: 1958:376). Frente a estas acciones incondicionadas, hay un movimiento desde el origen de la conciencia absoluta que refleja la existencia como posibilidad histórica en tanto certidumbre del ser-sí-mismo, es decir: "El origen en la conciencia absoluta es el movimiento activo por el cual se llega a ser sí-mismo" (Jaspers 1958:445).

De forma semejante, Heidegger escribe sobre el llamado de la conciencia a ser sí-mismo: "La conciencia se revela como llamado del cuidado: el vocante es el Dasein que, en su condición de arrojado (estar ya en...), se angustia por su poder-ser. El interpelado es este mismo Dasein, en cuanto llamado a su más propio poder-ser (anticiparse-a-sí...). Y el Dasein es llamado por la llamada para que salga de la caída en el uno (ya-estar-en-medio-del-mundo del que nos ocupamos)" (Heidegger 2015:299).

Ascendiendo con esto desde la caída en el uno, que según Jaspers se caracteriza por "la inautenticidad de vivencias y actitudes" (1958:446), por ejemplo, "la dispersión, la absolutización aisladora y la indecisión" (1958:31). Y que, en similar sentido, Heidegger sostiene que "el estado de caída en el mundo designa el absorberse en la convivencia regida por la habladuría, la curiosidad y la ambigüedad" (2015:200). Así entonces, la ascensión desde la caída en el uno mediante las acciones incondicionadas en situaciones límites y el correlativo movimiento desde el origen de la conciencia absoluta desde Jaspers, y por el llamado de la conciencia a ser existencia en el modo de sí mismo por parte de Heidegger, se expresan en la llegada a la existencia que para Jaspers es libertad, "la libertad es siempre el ser de la existencia" (1958:37) y esta se expresa como acción: "La libertad no se prueba por mi inteligencia, sino por mi acción" (1958:36). Acción que es elección y conquista de sí mismo o resolución: "esta elección es la resolución de ser yo mismo en la existencia empírica (...) Resolución y ser-sí-mismo son la misma cosa" (1958:40). En otras palabras: "En resolución experimento la libertad en la cual no solamente decido sobre algo, sino sobre mí mismo y no puedo separar la elección y el yo, sino que yo mismo soy la libertad de esta elección. La simple elección parece solamente una elección entre objetividades, pero la libertad es la elección de mí 
mismo. Así, pues, no puedo siquiera ponerme frente a mí y elegir entre mí mismo y no ser yo mismo, como si la libertad sólo fuera un instrumento para mí. No; en tanto que elijo, yo soy; si no soy yo no elijo" (1958:42).

Continuando con Jaspers, el autor plantea que el existente que se sabe libre es culpable (responsable), en el sentido de que yo respondo por aquello que hago. Culpa de la cual no se puede descubrir su origen, puesto que no sabemos cuándo comienza nuestra responsabilidad, pero está en el origen de nuestro ser al modo de que cuando nos reconocemos culpables ya estamos en la culpa, no obstante, es por la propia culpa que podemos ser libres: "es la necesidad de la culpa que parece suprimir la libertad, pero que, sin embargo, sólo existe para mí a causa de que, al asumir la responsabilidad, conservo mi libertad por el reconocimiento de mi culpa" (1958:57).

En Heidegger lo anterior se puede encontrar de la siguiente manera. En la facticidad de la condición de arrojado en cuanto ser ahí, el Dasein se encuentra originariamente caído en el uno. Mediante el llamado de la conciencia, el Dasein responde haciéndose culpable de su ser-ahí en cuanto responsable de ser el ser de un fundamento que no es el mismo, es decir, es responsable de su ser ahí, pero no el fundamento de este en cuanto arrojado: "siendo sí-mismo, el Dasein no es, él mismo, el fundamento de su ser en cuanto que este brotara de un proyectarse del propio Dasein, pero siendo sí-mismo, el Dasein es, sin embargo, el ser de este fundamento" (2015:305).

Responder a la llamada de la conciencia equivale a un comprenderse a sí mismo en su poder-ser-máspropio: "es elegirse a sí mismo (...) proyectarse en el más propio y auténtico poder-llegar-a-ser-culpable" (Heidegger 2015:308) o responsable de su ser. Pero el llamado de la conciencia es un llamado mudo que hace callar y genera angustia al Dasein al enfrenarlo a lo inconfortable de ser-sí-mismo y por el hecho de una eventual separación de la habladuría, curiosidad y ambigüedad del uno, y por ende la respuesta es en el modo de la resolución o el "callado proyectarse en disposición de angustia hacia el más propio ser culpable" (2015:326), existencial que es el modo propio del cuidado en cuanto ser del Dasein, concebido como "anticiparse-a-sí-estando-ya-en (un mundo) en-medio-de (los entes que comparecen dentro del mundo)". Este anticiparse a sí en el modo del proyecto, es posibilidad de ser sí mismo, y tiene a la muerte como "posibilidad de la imposibilidad de la existencia en general" (2015:284). En efecto, la posibilidad de la muerte es la: "posibilidad más propia del Dasein. El estar vuelto hacia esta posibilidad le abre al Dasein su más propio poder-ser, en el que su ser está puesto en juego (...) El adelantarse hace comprender al Dasein que debe hacerse cargo exclusivamente por sí mismo del poder-ser en el que está radicalmente en juego su ser más propio" (2015:284).

Desde la existencia se va hacia la conquista del ser, en términos de "la temporeidad que se revela como el sentido del cuidado propio" (2015:346), en el caso de Heidegger, para quien los éxtasis temporales dan sentido a los existenciales constitutivos del cuidado, a saber, "el anticiparse-a-sí (existencia) se funda en el futuro. El estar-ya-en (facticidad) ... acusa en sí el haber-sido (pasado). El estar-en medio-de (caída) ... es posible por la presentación (presente)" (2015:346). Se evidencia entonces cómo el ser-sí- mismo de la existencia se funda en el futuro, en cuanto, adelantarse a la posibilidad de la muerte para volver al ser culpable de su haber sido en el instante de la acción presentante.

Para Jaspers el ser tiene el sentido de la trascendencia que es la relación del existente con lo absoluto y que se manifiesta en las cifras, "la presencia de la trascendencia que está en el escrito cifrado" (1958:390), el cual se presenta como lenguaje con sentido individual, como mito y como metafísica. Finalmente, el fracaso de la permanencia de la existencia tiene relevancia como cifra de la eternización de la 
trascendencia cuando me esfuerzo por no fracasar: "La cifra de la eternización en el fracaso únicamente se hace clara cuando no quiero fracasar, pero me arriesgo a fracasar" (1958:608).

A este resumen esquemático y comparativo huelga sumar el énfasis de Jaspers en "la comunicación donde se patentiza la existencia" (1958:362), entendida como lucha amorosa donde se comunican dos existentes en su más propio ser sí mismo. Por su parte, Heidegger da énfasis al destino, que es también un destino común ya que estar-en el mundo es cooriginario con estar-con-otros, en tanto legado de la tradición como repetición en el instante de las posibilidades abiertas por otros Dasein. Destino, en palabras de Heidegger es "el acontecer originario del Dasein que tiene lugar en la resolución propia, acontecer en el que el Dasein, libre para la muerte, hace entrega de sí mismo a sí mismo en una posibilidad que ha heredado, pero que también ha elegido" (2015:402).

A modo de síntesis, se esboza una estructura tríadica en el pensamiento de Jaspers, a saber, existencia empírica, existencia en el modo de la libertad y trascendencia, en tanto existenciales fundamentales. La trascendencia en Jaspers es el ser que se expresa en las cifras, en cuanto símbolos no interpretables, sino que en sí mismos intuibles como manifestaciones de lo absoluto. La trascendencia entonces es la relación con lo absoluto mediante el lenguaje de las cifras, que es el primer lenguaje personal e inobjetable para cada existencia: "la lectura de las cifras como presencia originaria no se presta a método alguno" (1958:306), que al ser objetivado en el segundo lenguaje -al pasar al colectivo- se convierte en mito: "En el mito y la revelación, el método toma el camino de traducir las cifras originarias en objetividades específicas" (1958:306) y que en el modo de la comprensión por medio de la inteligencia es tercer lenguaje: "Si en el tercer lenguaje el pensamiento quiere promover su comprensión, entonces comienza como inteligencia" (1958:507), pero a cambio de perderse la verdadera relación con lo absoluto en dichas objetivaciones, puesto que esta relación es inobjetable. De ahí la imposibilidad de una ontología para Jaspers.

La existencia como posibilidad y libertad para este autor refiere a la posibilidad de elegirse a sí mismo en cada acción incondicionada, acciones donde se expresa la libertad del existente con respecto al existente meramente empírico: "la libertad existencial es la autocertidumbre del origen histórico de la decisión" (1958:45). El existente empírico en cambio, se rige por las acciones condicionadas reflejadas en la conciencia en general y en su estado de caída, donde priman los intereses egoístas por el espacio vital del existente empírico y no se logra la comunicación existencial, puesto que cada existente empírico es para otro existente empírico "homo homini lupus" (1958:259). El existente empírico es también el lugar de las objetivaciones científicas donde se expresa la escisión sujeto-objeto que en el existente como posibilidad es trascendida por la libertad en el modo de la resolución. Experimentar situaciones límite lleva al existente empírico a salir de su condicionamiento y realizar acciones incondicionadas que son expresión de la libertad, en otras palabras, las situaciones límites promueven el salto desde la caída, con su correspondiente conciencia en general, hacia el ser sí mismo en el modo de existencia histórica, con su correspondiente conciencia absoluta, en el sentido de una certidumbre de sí mismo en tanto sujeto histórico.

Por su parte, en Heidegger, se expresa de un modo similar a Jaspers, una estructura esencialmente tríadica en los existenciales constitutivos del cuidado, a saber, facticidad, existencia y caída: "El cuidado no caracteriza, por ejemplo, tan solo a la existencialidad, separada de la facticidad y de la caída, sino que abarca la unidad de todas estas determinaciones de ser" (2015:216). Estructura que adquiere sentido en la temporización, en cuanto despliegue de la temporeidad que se presenta como el horizonte de sentido donde se proyecta el cuidado en cuanto estructura ontológica del Dasein: "la temporeidad se revela como 
el sentido del cuidado propio" (2015:346). La caída es el movimiento del Dasein donde se encuentra en el modo del poder ser impropio: "En la caída no está en juego sino el poder-estar-en-el-mundo, aunque en el modo de la impropiedad" (2015:203), caracterizado por su absorción en el uno de lo público, al que le es propio la habladuría, la curiosidad y la ambigüedad. Desde ahí debe emerger el Dasein haciéndose responsable de su culpa, es decir, haciéndose responsable de su ahí, del cual el mismo no es el fundamento, a partir del llamado mudo de la conciencia, al cual el Dasein responde resolutivamente anteponiéndose a su muerte como su posibilidad más propia, lo que le permite reconocerse como ser de posibilidades, es decir, como proyecto. La temporización de su proyecto está dado desde el futuro, desde el cual se viene a ser lo que ya se era, pero como ser-sí-mismo, en la resolución precursora del presente, la cual repite o actualiza las posibilidades abiertas por la tradición en forma de legado, es decir, la cual cumple con su destino.

Así, comunicación en Jaspers y destino en Heidegger, son existenciales esenciales para entender la originalidad del pensamiento de cada autor, asimismo, las conceptualizaciones del ser como trascendencia en Jaspers (con la salvedad de que el autor afirma que no es posible una verdadera ontología) e hipotéticamente como tiempo en Heidegger. Por otro lado, las amalgamas de ambos autores residen en su interés mutuo por el esclarecimiento existencial a través del análisis de los existenciales que en cada autor puede ser pensado como un proceso complejo con recursividades que permiten la trascendencia desde la mera existencia empírica o disposición de arrojado hacia la existencia como proyecto y libertad fundados en la posibilidad como disposición común a ambos autores. Otro factor compartido es la relegación de la ciencia positivista a la existencia empírica o facticidad de la disposición de arrojado, y la pre-eminencia y trascendencia del ser del Dasein y de la existencia como libertad en relación a la escisión sujeto-objeto.

De estas consideraciones se deducen algunas sinergias entre el pensamiento de Jaspers y Heidegger que a modo de hipótesis permiten la emergencia de propiedades epistémicas originales relativas al concepto de ser humano, a la relación sujeto-objeto y a la relación investigador-investigado, que autorizan su proyección hacia el pensamiento epistemológico. En el siguiente apartado se esbozan las consecuencias sobre las estructuras mencionadas.

\section{Sinergias y proyecciones epistémicas}

Las sinergias y proyecciones que se analizan en este apartado, provenientes desde la consideración de los existenciales como disposiciones fundamentales del existente históricamente situadas, a diferencia de las categorías abstractas como fundamento ahistórico del pensamiento, permiten suponer las siguientes conceptualizaciones epistemológicas como estructuras onto-epistémicas en el sentido de ser disposiciones fundamentales histórica y culturalmente situadas del ser humano, de la relación sujetoobjeto (conciencia) y de la relación investigador-investigado (ética de la investigación). Cabe recordar que el corte epistémico realizado de las amalgamas entre el esclarecimiento existencial de Jaspers y el análisis existencial de Heidegger, dice relación con los límites de la estructura del formato artículo y con la comparación con las principales categorías que son motivo esencial de reflexión para la epistemología de las ciencias sociales y humanas.

\section{Ser humano}

Salta a la vista que el ser humano es la principal estructura epistemológica a considerar, puesto que no habría mundo si no hay seres humanos: "Ontológicamente el mundo no es una determinación de aquel 
ente que por esencia no es el Dasein, sino un carácter del Dasein mismo (...) Si no existiera ningún Dasein tampoco existiría mundo" (Heidegger 2015:94). En efecto, el mundo en el cual habita el Dasein originariamente en su condición fáctica de arrojado, adquiere el modo de la disposición afectiva y las posibilidades que la comprensión del ser humano proyecta en su ocuparse de los entes a la mano y de su tematización secundaria de los entes a la vista, donde dejan de ser posibilidades de utilización para ser simples datos. Por su parte, la interpretación, en tanto articulación de la comprensión afectivamente dispuesta de los entes intramundanos, que en su respectividad son signos, se expresa en el discurso. En palabras de Heidegger, "la constitución ontológica de la aperturidad que pertenece esencialmente al Dasein (...) Su ser se constituye en la disposición afectiva, el comprender y el discurso" (2015:204). En tanto existenciales de la aperturidad fáctica del Dasein, la disposición afectiva, el comprender, la interpretación y el discurso se fundan en el estar-en-el-mundo, es decir, a la originaria situacionalidad del ser del ahí, la cual no refiere a una situacionalidad meramente espacial de un ser-ahí, sino al originario "habitar en... estar familiarizado con..." (2015:83) del estar-en-el-mundo en tanto disposición esencial del Dasein.

En el mismo sentido que Heidegger, vemos cómo se puede generar una crítica al ser humano racional y objetivo que supone la ciencia tradicional, desde la disposición del ser humano como existente empírico. Según Holzapfel, el Dasein es comprendido por Jaspers como "ser ahí nomás" (2014:154), es decir, como el existente empírico y cognoscente, con su correlativa conciencia vivencial y conciencia en general de las objetivaciones científicas que permiten una orientación mundanal. Según Jaspers: "La conciencia, en tanto que vivencia, es la realidad individual de la existencia empírica; en tanto que conciencia en general, es la condición universal de toda objetividad para el sujeto cognoscente" (1958:133). No obstante, se puede colegir que este ser-ahí nomás situado en el mundo afectiva y cognoscitivamente es ya una superación del ser humano ausente de la ciencia tradicional, puesto que la narrativa canónica de la ciencia positivista hegemónica es en tercera persona, conocida como el sujeto ausente, ya que este tipo de narración provoca la impresión fenoménica de objetividad, empirismo y neutralidad del investigador, a costa de la desaparición de la humanidad del mismo, con toda su complejidad afectiva, volitiva y comportamental. Justamente, mediante el artilugio de la narración en tercera persona, la humanidad del investigador con todas sus coloraturas afectivas desaparece, cayendo su comprensión en la comprensión de la conciencia en general. Correlativamente, el mundo se vuelve un mundo de valores opacos con polos dicotómicos en blanco y negro, con lo que se trivializa el objeto de conocimiento perdiéndose con esto la complejidad del mismo, que es cooriginariamente la complejidad del sujeto.

El Dasein comprendido desde Heidegger es ya la existencia como posibilidad en Jaspers. Recordemos la estructura ontológica del cuidado que es el ser del Dasein, y en el cual se incluye la condición de arrojado identificada con el pasado, la condición de caída ubicada en el presente y la condición de existente como proyecto, ubicada en el futuro. Para Jaspers, el existente es posibilidad y libertad en cuanto la libertad es poder-ser-sí-mismo y este es de forma similar al Dasein, un ser histórico. Por ende, solo en la resolución con conciencia histórica, fundada a su vez en el existente empírico es que el existente empírico se hace ser-sí-mismo. Se refuerza con esto la idea de la situacionalidad que en términos prácticos sería la construcción de una narrativa científica en primera persona y explicativa de las condiciones de producción de conocimiento (situacionalidad). En síntesis, contra el ser humano ausente, emerge el existente como ser humano situado: "Toda existencia es comprensiva, concreta; y también toda concepción del mundo que es proporcionada a ella. Esta nunca puede ser, por esta razón, 'verdadera' y 'absoluta', como las formas intemporales, sino que en todo tiempo y de una forma absoluta es vivida potencialmente como superable ya en cada forma de la existencia" (Jaspers 1967:52). 
Pero no solamente un ser humano situado, sino también un ser humano que, a partir de su situacionalidad, se proyecta libremente en su ser, de lo que a modo de hipótesis provisoria se deriva una construcción de conocimiento enfocada en las posibilidades que se hacen efectivas en el proyecto más que en la realidad derivada de la presencia de los entes como meros seres ahí. Reflexión que se obtiene de la concepción de "ser humano como proyección" que Holzapfel (2014:154) teoriza a partir de Jaspers y Heidegger. Esto se puede esbozar de la siguiente manera: A la vez que el sujeto se proyecta a sí-mismo estando ya en el mundo entre los entes intramundanos, se proyecta libremente en la construcción de conocimiento como posibilidades efectivas de ser de los entes intramundanos, ocupándose de los entes a la mano y teorizando los entes que dejaron de ser a la mano para hacerse presentes objetivamente.

\section{Relación sujeto-objeto}

Al contrario de la simplificación de la relación sujeto-objeto como simple isomorfismo o correspondencia entre uno y otro, con énfasis en lo objetivo en desmedro de un sujeto ausente; obtenemos desde Jaspers una conceptualización compleja de la mentada relación que en esencia es constitutiva de la conciencia. El autor sostiene que en primer lugar la relación sujeto-objeto es más bien una escisión sujeto-objeto, puesto que presupone una unidad originaria de sujeto y objeto en la corriente vivencial subjetiva: "El acontecer anímico en su totalidad significa corriente vivencial, realidad vivencial, vida inmediata, experiencia originaria, etc. (...) En esta corriente estaría enmarcado el protofenómeno de que el sujeto se contraponga a los objetos. Nuestra vida discurre en esta disociación sujeto-objeto" (Jaspers 1967:44).

La escisión sujeto-objeto es una relación móvil, nunca se es completamente objetivo ni completamente subjetivo, y asimismo los diversos modos de lo objetivo dependen de lo subjetivo y viceversa. Asimismo, entre sujeto y objeto no hay una línea directa, sino algo así como rejillas a priori o formas trascendentales donde se funda la corriente vivencial y que permiten un determinado modo de relación entre sujeto y objetos: "según a través del enrejado que mire el sujeto, así verá tipos específicos de objetos y se encontrará psicológicamente en un modo específico de vivencia. Cada uno de los enrejados pueden ponerse encima de todo, no tienen límites; y en cada caso los objetos aparecen objetivamente de un modo especial. El caudal vivencial fluyente, en tanto que lleva en sí disociaciones sujeto-objeto, está conformado dentro de éstas y depende de los enrejados fijos, cristalizantes de estas formas intemporales, improducidas, imperecederas, válidas, condicionantes, porque sus objetos sólo son en cuanto objetos" (Jaspers 1967:50).

Pero estas condiciones a priori son solo formales, la elección de uno y otro modo depende de la fuerzas, ideas, espíritus, ideas o valores que al poseer al existente activan determinados modos de escisión sujetoobjeto y recursivamente emergen desde dicha relación: "De las fuerzas surgen disociaciones sujeto-objeto específicas y estas, por su parte, despiertan nuevas fuerzas" (Jaspers 1967:51). Entre formas trascendentales y espíritus fundados en la corriente vivencial, las primeras son atemporales, las segundas en cambio varían históricamente y de existente en existente. Con respecto a los grados de la polaridad entre subjetividad y objetividad, encontramos en el polo de lo objetivo: "objetividad (exterioridad), validez (generalidad) e idea (totalidad)" (Jaspers 1958:236), los cuales presuponen uno a otro. En el polo de la subjetividad emergen el estado de conciencia en general (interioridad), el de la conciencia de la validez (ente racional, persona) y el del ser empírico individual (casualidad, capricho, voluntad propia) (1958:236), en tanto grados de subjetividad que se contraponen punto a punto con los grados de la objetividad, a saber, interioridad-exterioridad, ente racional-generalidad, voluntad propia-totalidad. 
A través de los grados de contraposición, podemos encontrar tipos regulares de escisión sujeto-objeto, las cuales Jaspers denominó concepciones de mundo, compuestas de actitudes subjetivas e imágenes objetivas. En estas modalidades de la relación se objetivan las múltiples formas que adquiere la escisión sujeto-objeto a través de los grados de contraposición, producto de "fijaciones, tránsitos, flujos, reflujos, contrariedades, armonías y transposiciones" (Holzapfel 2015:27) entre estos dos polos. Holzapfel resume los modos de relación entre actitudes subjetivas e imágenes objetivas de mundo con el siguiente esquema en su libro "El enlace hombre-mundo (exploración filosófica existencial en la perspectiva de Jaspers)" y que aquí reproducimos a modo de ilustración de la complejidad de la escisión sujeto-objeto que nos entrega Jaspers y, por ende, de las múltiples posibilidades que se abren para su estudio:

“1. Actitudes objetivas, en las que el objeto tiene una primacía. A su vez estas actitudes objetivas pueden ser:

1.1. Activa, que considera el objeto como algo modificable a su manera.

1.2. Contemplativa, que más bien deja ser al objeto tal cual es. Ella puede ser a su vez:

1.2.1. Intuitiva, que capta del objeto lo esencial.

1.2.2. Estética, que transfigura al objeto como un todo.

1.2.3. Racional, que del objeto abstrae sólo algunos elementos.

1.3. Mística, en la que el sujeto se funde en el objeto (lo divino).

2. Actitudes autorreflexivas, en las que el sujeto tiene una primacía:

2.1. Autorreflexión contemplativa: cómo nos contemplamos.

2.2. Autorreflexión activa: cómo nos queremos.

2.2.1. Gozadora: actitud que se orienta al goce del objeto.

2.2.2. Ascética: actitud que más bien goza de la abstención del objeto.

2.2.3. Autoconformación (Selbstgestaltung) del sí-mismo a través de negaciones y afirmaciones, goce y abstención.

2.3. Actitud reflexiva y actitud inmediata: el instante. Ella tiene que ver con la percepción del objeto y del mundo en cuanto a un apego a lo inmediato, o de manera reflexiva. En ello se juega también cómo temporalizamos el tiempo y cómo nos vinculamos con el instante.

3. Actitud entusiástica: el sujeto se eleva al común encuentro en una unidad superior junto con el objeto, que aquí pasa a ser otro sujeto, como sucede particularmente en el amor.

A su vez, digamos escuetamente que por el lado de las imágenes de mundo habría:

1. Imagen de mundo sensoro-espacial, entre las cuales se cuenta con una imagen de mundo:

1.1. Natural-mecánica.

1.2. Natural-histórica.

1.3. Natural-mítica.

1.4. Técnica.

2. Imagen de mundo anímico-cultural.

3. Imagen de mundo metafísica" (Holzapfel 2015:23-24).

La existencia como libertad no se encontraría ni en el sujeto ni en el objeto, sino que abarcaría aquella polaridad, trascendiendo el límite de esta relación. El sí mismo sería así una síntesis entre la generalidad de la objetividad y la singularidad de la subjetividad: "Devenir del sí mismo significa que lo universal deviene en lo singular y ninguno de los dos es dejado a un lado" (Jaspers 1967:540). La siguiente cita es elocuente en lo que respecta a la importancia de la comprensión de la trascendencia del límite de la escisión sujeto-objeto para conquistar la existencia como ser-sí-mismo: "La existencia está siempre en la completa polaridad de subjetividad y objetividad, no sólo en uno de los lados. La polaridad de lo subjetivo y objetivo culmina para la orientación intramundana, trascendiendo ya en su límite, en la objetividad de la idea de la realidad empírica del mundo y en la subjetividad de la idea de cada personalidad singular. La 
«existencia» ingresa en la objetividad participando en las ideas, las cuales tienen su realidad como espíritu. Ingresa en la subjetividad al manifestarse en el individuo como idea de su personalidad, sin llegar por eso a identificarse con ella. Yo no soy mi idea, pero yo me realizo en ella. La aclaración de la "existencia» en la realización activa no se consigue en la comunicación sin objeto de los meros individuos, tampoco en la objetividad de la realidad empírica del mundo como todo contemplado y producido, sino participando en ambas: en la absoluta singularidad individual de mi existencia empírica en comunicación con otros individuos y en las objetividades del mundo, en el que encuentro a los otros individuos" (Jaspers 1958:240).

Evidentemente, el planteamiento de Jaspers sobre la escisión sujeto-objeto tiene directas implicancias para la epistemología en cuanto abren la posibilidad de un salto cualitativo respecto al estudio de la relación sujeto-objeto. Por lo demás, a este planteamiento se amalgama sinérgicamente el pensamiento ontológico de Heidegger quien hace patente la necesidad de una aclaración onto-epistemológica previa a cualquier tipo de planteamiento epistemológico: "Toda idea de sujeto -si no está depurada por una previa determinación ontológica fundamental- comporta ontológicamente la posición de subjectum, por más que uno se defienda ónticamente en la forma más enfática contra la sustancialización del alma o la cosificación de la conciencia. La coseidad misma tiene que ser previamente aclarada en su procedencia ontológica, para que se pueda preguntar qué es lo que debe entenderse positivamente por el ser no cosificado del sujeto, del alma, de la conciencia, del espíritu y de la persona" (Heidegger 2015:73).

Pues bien, sabemos que la constitución ontológica del Dasein es el cuidado, estructura existencial que a la vez se compone de la condición de arrojado como apertura fáctica en el mundo (pasado), existencia como proyecto (futuro) y caída en la medianidad (presente). En este sentido, la ciencia tradicional estaría dada en la caída, la que a su vez se funda en la condición de arrojado desde donde se harían presentes los entes como ya sidos. Desde aquella estructura existencial, los entes del mundo son concebidos como "puramente presente" (Heidegger 2015:164) u objetividades, es decir, como objetos presentes en dos sentidos, como presentes ahí y como estando en tiempo presente. Pero el tiempo como sentido del cuidado requiere comprender los entes en función de su temporización. En efecto, el ser de los entes no estaría en la caída donde los entes del mundo aparecen en el modo de presencia objetiva, sino en la existencia donde encuentran su ser como útiles a la mano en función del proyecto del Dasein, es decir, en el éxtasis temporal del futuro que Heidegger llama "adelantarse o precursor" (2015:356). Así entonces, para el Dasein en tanto ser que se proyecta en el mundo, los entes del mundo son originariamente útiles a la mano y en un segundo momento objetos a la vista, luego de una interrupción de la ocupación del Dasein con sus útiles, en que estos se vuelven inútiles. Cabe señalar que esto no quiere decir que solo en el segundo momento haya teorización y en el primer momento solo práctica, sino que la ocupación con los entes supone ya una comprensión de estos como útiles a la mano: "El comportamiento práctico no es ateorético en el sentido de estar privado de visión, y su diferencia frente al comportamiento teórico no consiste simplemente en que aquí se contempla y allí se actúa y en que el actuar, para no quedarse a ciegas, aplica un conocimiento teorético; por el contrario, la contemplación es originariamente un ocuparse como el actuar también tiene su propia visión" (Heidegger 2015:99).

Así, los entes toman primariamente sentido desde el futuro proyectado por el Dasein, desde el que viene a ser lo ya sido, es decir, viene a ser la aperturidad efectiva de su condición de arrojado, pero digamos ahora con conocimiento de la instrumentalidad de los objetos en la efectivización de sus posibilidades en el instante presente. Digamos a modo de hipótesis, que es posible considerar la corriente de conciencia en Jaspers como un existencial cooriginario al ser-en-el-mundo del Dasein, lo que permitiría entender la escisión sujeto-objeto en la conciencia como correlato de la interrupción de la ocupación con los entes a 
la mano en el contexto del proyecto existencial, y a su vez, comprender la codependencia de sujeto-objeto como un correlato en la conciencia de la utilizabilidad originaria de los entes en el mundo para el Dasein. Asimismo, las diferentes modalidades en que se presenta la relación sujeto-objeto pueden ser considerados correlatos de posibles modos en que los entes se presentan como útiles en el contexto del proyecto existencial del Dasein.

Claramente vemos posibilidades de sinergia epistémica en amalgamar hipotéticamente las reflexiones de Heidegger y Jaspers asociadas a la relación sujeto-objeto, lo que implicaría la historización de las formas trascendentales en tanto formas atemporales: "lo verdadero y absolutamente válido de las formas trascendentales es al mismo tiempo lo intemporal" (1967:52) que plantea Jaspers con base en Kant (tiempo, espacio, cantidad, cualidad, relación, modalidad), y a su vez, una historización de los rastros de la cosa en sí que podrían vislumbrase a partir de dicha influencia, pasando a considerar la escisión sujetoobjeto como una relación donde se captan la esencia de las cosas como útiles a la mano con su correlativa manifestación en la conciencia como dependencia del sujeto por parte del objeto. Con esto se hace patente la necesidad de pensar los efectos de la temporización de los grados y modalidades de la escisión sujeto-objeto. Por consiguiente, vemos como los planteamientos epistemológicos de Jaspers se amalgaman sinérgicamente con los planteamientos ontológicos de Heidegger, lográndose sinergias evidentes y proyecciones epistemológicas con consecuencias indirectas para disciplinas como la psicología y la antropología, por ejemplo.

\section{Relación investigador-investigado}

Con base en la certeza de que toda relación social se funda y es mediada por la comunicación, y siendo la investigación científica en lo esencial un determinado modo de relación social, es posible sostener que la investigación se funda y es mediada por un determinado modo de comunicación. A su vez, como vimos, basado en una concepción situada y proyectante de ser humano, el conocimiento debe tener como fundamento la situacionalidad del ser humano y como fin la construcción de posibilidades de ser-sí mismo y de los entes intramundanos. Por consiguiente, y a modo de suposición, la disposición epistemológica que cumpliría plenamente con estos criterios es la comunicación existencial, planteada por Jaspers también como lucha amorosa que viene a ser la realización del sí-mismo: "El hecho de que la certidumbre del ser sólo brote de la lucha por la patentización es la situación límite para la existencia en la existencia empírica, en la cual puede llegar a la más profunda conciencia de sí misma, pero también a la desesperación radical. El hecho de que, aun allí donde parezco ser yo mismo, la puesta en cuestión sea condición para llegar a ser verdaderamente real en el tiempo exige esta lucha. Pues en la manifestación nada es existencialmente definitivo. La existencia es lo que realmente es porque se descubre en la situación límite de la lucha reveladora. La comunicación existencial, entendida como este proceso de lucha, nacida de la preocupación por el auténtico ser, es la realización de este ser" (1958:115).

Para el autor, la comunicación existencial se da entre existentes que luchan por la patentización de su existencia, llegando a lo más profundo del ser sí mismo del otro, mediante la incondicionalidad, la lucha sin violencia y la solidaridad. Con respecto a la incondicionalidad Jaspers afirma que: "La comunicación de la existencia se realiza únicamente desde la incondicionalidad a la incondicionalidad y en la armonía de la incondicionalidad consigo misma" (1958:280). Recordemos que la incondicionalidad refleja la libertad en los actos del existente como posibilidad. En relación a la ausencia de violencia el filósofo sostiene que: "en esta lucha no hay violencia alguna. No hay victoria o derrota de una de las partes; victoria y derrota son comunes. La victoria no se consigue por superioridad sino por virtud de la conquista común en la 
patentización. La derrota no se produce por defecto de la fuerza, sino por hurtarse y esconderse al no estar dispuesto a sufrir la crisis del querer propio y ajeno" (1958:116).

La solidaridad es fundamental en la lucha amorosa en cuanto comunicación existencial puesto que permite la verdadera comunicación entre el más propio ser sí mismo de cada existente: "esta lucha, al ser la más radical puesta en cuestión del otro y de mí mismo solo es posible sobre la base de una solidaridad que supone incuestionablemente lo mismo en el otro que en mí la posibilidad de la existencia" (Jaspers 1958:116). Por otro lado, hay desviaciones de la comunicación existencial que confluirían en una comunicación entre existentes empíricos donde se efectúa no una lucha amorosa por la mutua patentización, sino por la supervivencia y el espacio vital. En efecto, dichas desviaciones son: "la superioridad intelectual que se traduce en violencia; la pasividad del que se somete sin condiciones; la obliteración ofendida del que se encierra en sí, utilizando el no responder como medio violento de lucha; las preguntas sofísticas y el desviarse en pláticas puramente objetivas que no tienen término; la mera solicitud caballeresca y la preocupación por la formación educativa; la resignación callada; la piedad de la compasión y de la ayuda externa" (Jaspers 1958:118).

Todas las acciones nombradas tienden hacia la cosificación de la comunicación, a las que se puede agregar la pretensión de objetividad y neutralidad por parte del investigador. Con esto en mente, y considerando las anteriores elaboraciones, podemos considerar una relación entre sujeto investigador y sujeto de investigación fundada en la incondicionalidad, no violencia y solidaridad entre investigador e investigado y en la negación de las desviaciones hacia una comunicación meramente empírica.

A estos planteamientos es posible agregar desde Heidegger el co-existir con otros Dasein, existencial que hace referencia al hecho de que, así como de manera originaria no hay un sujeto sin mundo, "tampoco se forma inmediata un yo aislado sin los otros" (2015:143). Los otros son para el Dasein no entes a la mano ni cosas a la vista, sino otros Daseins que deja en libertad que también existan y existen con él. Por ende, no puede responder a este ente en el modo de la ocupación en cuanto absorberse en la utilización de los entes a la mano, sino que en el modo de la solicitud: "Ser uno para otro, estar uno contra otro, prescindir los unos de los otros, pasar el uno al lado del otro, no interesarse los unos por los otros, son posibles modos de la solicitud" (Heidegger 2015:148) que caracterizan la medianidad del coexistir de los Daseins. En los extremos de sus posibilidades, la solicitud puede ser sustitutivo dominante o anticipativa liberadora en cuanto que en la primera se quita al otro el cuidado reemplazándolo en su quehacer, es decir, sustituyéndolo en su sitio y objeto del cuidado, en cambio en la segunda posibilidad de la solicitud se devuelve al otro el cuidado anteponiéndose a su poder ser sí mismo y más aun promoviéndolo. En palabras de Heidegger: "esta solicitud, que esencialmente atañe al cuidado en sentido propio, es decir, a la existencia del otro, y no a una cosa de la que él se ocupe, ayuda al otro a hacerse transparente en su cuidado y libre para él" (2015:149). En este sentido, a la solicitud anticipativo-liberadora le es propia el respeto y la indulgencia en cuanto existencial del co-existir.

Considerando lo anterior podemos entonces elaborar una fórmula provisoria para la relación entre sujeto investigador y sujeto de investigación, a saber, la relación entre investigador e investigado en tanto comunicación existencial se funda en un originario co-existir con otros en el modo de la solicitud anticipativo-liberadora, a la cual le es propia la incondicionalidad, no violencia, la solidaridad, el respeto y la indulgencia entre investigador e investigado. Esta comunicación es fundamento y medio para llegar a ser sí-mismo por parte de los existentes y para la construcción de conocimiento genuino. Ahora bien, este llegar a ser sí mismo y la construcción de conocimiento genuino requieren de una comunicación existencial fundada en un co-exisistir situado históricamente en el mundo. Y esto puesto que toda comunicación 
existencial y en particular la comunicación existencial dada entre investigador e investigado se da originariamente en una comunidad semiótica con una determinada tradición cultural o patrimonio que entrega un legado discursivo a los interlocutores, el cual se traduce en posibilidades abiertas por la tradición que siendo asumidas se repiten originalmente en el presente en tanto destino común de los interlocutores pertenecientes a dicha comunidad. Por lo tanto, la comunicación existencial entre investigador e investigado tanto si pertenecen a una misma comunidad territorial, generacional, nacional, etc., como si se reconocieran perteneciendo a comunidades distintas (en donde se daría una comunicación intercultural), deben interpretar la comunicación a partir de la tradición discursiva en que ambos interlocutores se reconocen, permitiendo así la conquista del sí mismo desde las posibilidades abiertas por dicha tradición y el surgimiento de un conocimiento genuinamente arraigado.

\section{Conclusión}

Si a lo anterior agregamos las conjeturas realizadas en el concepto de ser humano y en la relación sujetoobjeto, podemos elaborar la siguiente propuesta epistemológica derivada del pensamiento de Jaspers y Heidegger, a saber, la investigación científica se fundamenta en la situacionalidad histórica de las personas, en la complejidad situacional de sus conciencias, y en una comunicación existencial fundada a su vez en un originario co-exitir con otros en el modo de la solicitud anticipativo-liberadora, a la cual le es propia la incondicionalidad, no violencia, la solidaridad, el respeto y la indulgencia. Situacionalidad histórica de investigador e investigado, complejidad situacional de sus conciencias y comunicación existencial históricamente situada entre ambos, posibilitarían la conquista de la libertad de cada persona y la construcción de conocimiento genuinamente arraigado en la tradición de una determinada comunidad semiótica.

Hemos visto como a partir de las amalgamas existenciales entre el esclarecimiento de la existencia de Jaspers y la analítica existencial de Heidegger es posible deducir una concepción situada de ser humano, una relación sujeto-objeto compleja y una relación entre investigador e investigado fundada en la comunicación existencial. Claramente estas proyecciones son una esquematización en función del formato de escritura, lo cual simplifica consecuencias epistemológicas mucha más amplias en sus posibilidades. En efecto, en este trabajo se esbozaron proyecciones que evidentemente deben ser desarrolladas, por ejemplo, en lo relativo a la historización de las formas transcendentales y las fuerzas espirituales, así como la temporización de la escisión sujeto-objeto en la conciencia.

Por otro lado, es patente que el esclarecimiento de la existencia y la analítica existencial ya son por sí mismos fuentes inagotables de recursos para desarrollar un análisis propio en función de llegar a ser sí mismo.

Con todo, se abre la pregunta de si estamos en lo correcto al plantear que este trabajo intenta continuar con el espíritu de la comunidad de lucha iniciada por Jaspers y Heidegger. Así como en su tiempo ambos autores fundaron y contribuyeron a un giro de la esencia a la existencia en la filosofía, hoy en día ¿debemos promover un giro desde la ciencia monodisciplinaria con base en las esencias hacia una ciencia transdisciplinaria fundada en la existencia?, ¿la lucha debe ser hoy en día en el ámbito de la ontoepistemología?, y si esto es así, ¿debemos mantener una postura negativa con respecto a la posibilidad de una ontología o refugiarnos en una objetivación del ser?, ¿debemos ceder ante la cuantificación del pensamiento o resistir en lo comprensivo?, y si es que las preguntas prefiguran el sentido de la respuesta, ¿cómo hacer las preguntas adecuadas?, ¿cuáles son las preguntas genuinas? y en definitiva, ¿qué preguntas debemos ser? 


\section{Bibliografía}

Heidegger, M. 2015. Ser y tiempo. Santiago: Editorial Universitaria.

Holzapfel, C. 2001. Conciencia absoluta y acción en Jaspers. Philosophica 24-25: 79-115.

www.philosophica.ucv.cl/holzapfel24.pdf

Holzapfel, C. 2007. La "comunidad de lucha" Jaspers-Heidegger. Auge y caída de una amistad. Revista de filosofía 63: 139-156. doi: 10.4067/S0718-43602007000100011

Holzapfel, C. 2014. Ser-humano (cartografía antropológica). Santiago: Cinta de Moebio Ediciones.

Holzapfel, C. 2015. El enlace hombre mundo. Exploración filosófico-existencial en la perspectiva de Jaspers. Santiago: Cinta de Moebio Ediciones.

Jaspers, K. 1958. Filosofía II. Madrid: Ediciones Revista de Occidente.

Jaspers, K. 1967. Psicología de las concepciones del mundo. Madrid: Editorial Gredos.

Recibido el 29 Nov 2016

Aceptado el 4 Ene 2017 